\title{
Acerca del renovado interés por Karl Polanyi
}

\author{
Sobre o interesse renovado de Karl Polanyi
}

Joan Subirats ${ }^{1}$

\begin{abstract}
Resumen
¿Cómo es posible que un libro escrito hace setenta años despierte hoy un renovado interés y que sirva para hacer mejores diagnósticos sobre la crisis económica y sus posibles alternativas? En este texto trataremos de dar respuesta a este interrogante, mostrando los elementos que hacen de la obra de Polanyi un buen punto de partida para observar la crisis de legitimidad política y los problemas de relación entre economía de mercado y sistema político. La crítica de Polanyi a la naturalización de la economía de mercado es hoy plenamente actual.
\end{abstract}

Palabras-clave: Karl Polanyi. Economía de Mercado. Capitalismo. Bienes Comunes. Crisis Económica. Relaciones Estado y Sociedad.

\section{Resumo}

Como poderia um livro escrito há setenta anos atrás, hoje despertar um interesse renovado e útil para fazer melhores diagnósticos da crise econômica e suas possíveis alternativas? Este texto tenta responder esta questão, mostrando os elementos que fazem o trabalho de Polanyi um bom ponto de partida para observar as crises de legitimidade política e dos problemas de relação entre economia de mercado e sistema político. A crítica de Polanyi à naturalização da economia de mercado é hoje totalmente atual.

Palavras-chave: Karl Polanyi. Economia de Mercado. Capitalismo. Bens Comuns. Crises Econômica. Relações de Estado e Sociedade.

\section{¿Quién es Karl Polanyi?}

La trayectoria vital del intelectual húngaro, Karl Polanyi se enmarca necesariamente en la confusa y atribulada historia europea de la primera mitad del siglo XX. Trabajando en estas notas, he recordado muchas veces un texto de Stefan Zweig, escrito desde el que sería su último destino en Florianópolis (Brasil), El mundo de ayer (ACANTILADO, 2002, Madrid). Las trayectorias de Polanyi y Zweig son distintas, pero comparten origen centroeuropeo, tradición judía y vicisitudes vitales a caballo de guerras, emigraciones forzadas y una indomable voluntad por no dejarse arrastrar por la senda que marcan otros, sin pensar, reflexionar y sacar conclusiones.

Texto enviado en 13 de febrero de 2014 y aprobado para publicación en 9 de mayo de 2014.

\section{DOI: http://dx.doi.org/10.1590/1679-395116466}

1 Doctor en Ciencias Económicas; Catedrático de Ciencia Política del Departamento de Ciencia Política e investigador y responsable del Programa de Doctorado del Instituto de Gobierno y Políticas Públicas de la Universidad Autónoma de Barcelona. Dirección: Passeig d'Urrutia, 17 - 08042, Barcelona, Spain. E-mail: Joan.subirats@uab.cat 
Como dicen Marguerite Mendell y Kari Polanyi Levitt (2012) en un denso y elaborado artículo sobre su obra, "Polanyi creía en el poder del cambio conseguido por la gente común", o lo que es lo mismo, la capacidad de los ciudadanos para diseñar su propio futuro. No parece aventurado decir que su propia trayectoria vital le confirmó esa aseveración. Nació en la Viena del Imperio Austro-Húngaro en 1886, pero creció en Budapest, en cuya universidad se formó. Allí formó parte del influyente Círculo Galilei, con intelectuales como Lukács o Manheim. Después de una participación para nada ligera en la I Guerra Mundial, recaló nuevamente en Viena, participando siempre en los intensos y hasta cierto punto confusos movimientos de la izquierda europea, con influencias cruzadas del marxismo, del fabianismo o del socialismo cristiano. Fue allí en Viena, cuando empezó a polemizar con la influyente escuela económica austríaca, encabezada por Ludwig von Mises y su famoso discípulo Friedrich Hayek, que en pleno descrédito del capitalismo tras la Gran Guerra, el surgimiento de la Unión Soviética y el gran atractivo del socialismo, trataron de reivindicar las virtudes del mercado autorregulado.

La trayectoria ideológica de Polanyi no fue para nada lineal, y expresa bien la idea que aquellos intelectuales que viven con intensidad y compromiso su devenir vital, muestran muchas veces giros y matices hasta cierto punto contradictorios. Lo que no ocurre, en cambio, con aquellos que mantienen inalterables sus principios y convicciones a cambio de no someterse constantemente a la prueba del contraste con la realidad. Como explican Mendell y Polanyi-Levitt, en una carta casi póstuma escrita en 1962, Polanyi decía: "El desarrollo de las ideas puede ser presentado de dos maneras; ya sea cronológicamente, o en la dirección inversa, siguiendo los elementos esenciales hasta sus orígenes". Afirma entonces que la secuencia cronológica no acostumbra a funcionar adecuadamente cuando transcurre por décadas conflictivas y llenas de disrupciones fundamentales. "La otra manera de clarificar ideas es la de seguirles la pista desde los diseños acabados a los orígenes de las distintas líneas argumentales" (énfasis en el original). Habla de polaridades existenciales: "empirismo y normatividad; sociedad y comunidad; ciencia y religión. Las direcciones cambiaban a medida que eran puestas a prueba en la vida, en el pensamiento, en la historia...parece que esta polaridad formó el eje permanente de mi esfera de pensamiento".

Pero, por encima de esos trazos discontinuos y complejos, Polanyi muestra unas constantes ideológicas notables: preocupación por la libertad, el reconocimiento a los aspectos centrales de la cultura popular, la necesaria búsqueda de un socialismo humanista como expresión verdadera de la democracia. Desde ahí se entiende mejor su constante reiteración por un sistema económico que no se aparte de su enraizamiento, de su incrustación en la sociedad. En efecto, el sentir profundo de la obra de Polanyi es la convicción de la inaceptabilidad de la naturalización de la economía de mercado como algo fuera de la voluntad y acción social, que actúa y opera con reglas que se presentan como inmutables, a las que deben plegarse estados y comunidades.

La llegada de Hitler al poder, en 1933, provocó la salida de Polanyi del semanario en el que colaboraba en Viena, y, como tantos otros, emprendió el camino del exilio. Se instaló en Londres, y participó muy activamente como profesor en los cursos para trabajadores que patrocinaban las universidades de Oxford y Londres. La preparación de esos cursos le permitieron profundizar sobre la historia de la industrialización inglesa, que tan importante papel juega en su obra más significativa, "La gran transformación". No podemos decir que fuera casual que su visión de primera mano sobre la condición de la clase obrera en Inglaterra, y la clara posición subordinada, educativa, social y económica, de los trabajadores ingleses, no le llevara a conectar esa realidad con las debates teóricos que el mismo había ya sostenido con adalides tan significativos del liberalismo económico como Von Mises o Hayek. La "sociedad de mercado" que el rastreaba en su quehacer diario de profesor de trabajadores, contrastaba con la visión utópica y dogmática del mercado autorregulado.

En efecto, en sus escritos fue consolidando la idea que el capitalismo liberal o la economía de mercado, tenía características intrínsecas que lo hacían vitalmente incompatible con la realidad siempre social de los seres humanos. La mirada aparentemente racional y estrictamente individual que fundamenta la lógica competitiva de mercado, lo que provoca es una difuminación de las relaciones interpersonales, haciendo desaparecer los elementos de responsabilidad de cada uno ante lo que se entiende como fuerzas objetivas del intercambio mercantil. Nadie sería responsable de lo que le ocurre a otras personas, o de lo que provoca la actividad 
económica en el habitat natural circundante. Las alternativas autoritarias, tampoco satisfacen sus ideales, ya que sacrifican el aspecto clave de la libertad y de la responsabilidad de cada quién.

Es en sentido bien conocida su tesis del "doble movimiento". Por un lado el mercado se expande continuamente, pero ese movimiento se contrapone a otro que busca responder a los problemas que genera la dinámica puramente económica en la fábrica social, en la constante ruptura y tensión que genera el mercado aparentemente autorregulado en la articulación de relaciones sociales. Ese contra movimiento es, de hecho, la voluntad de autoprotección, como respuesta instintiva de la sociedad de salvar su propia naturaleza y sus propias dinámicas productivas, basadas no solo en el intercambio, sino también en la reciprocidad y la redistribución.

Como afirma José Luis Coraggio (2012) en sus comentarios sobre la relación entre Polanyi y la dinámica de la economía social en América Latina, hoy parece claro lo que anticipaba Polanyi, globalizar la economía como una economía de mercado es una utopía, e intentar llevalo a cabo es autodestructivo. Por eso Polanyi ha sido "redescubierto", ya que explica lo que sucede desde su perspectiva analítica e histórica, y ofrece claves para dar respuestas. Así: toda sociedad tiene procesos económicos, que implican producción, distribución y consumo. Una sociedad no perdura sino institucionaliza de alguna manera tales procesos de forma que aseguren la subsistencia, su reproducción y la de las condiciones materiales y de habitat necesarias para ello. Será fundamental determinar tanto el valor económico como la creación del poder. Las economías son actualmente construcciones políticas, y no meras evoluciones naturales. La sociedad debe decidir democráticamente esas construcciones. El cambio tecnológico forma parte insoslayable de esa dinámica. Repensar la economía desde las necesidades y relaciones sociales, y no desde su aparente neutralidad y naturalidad, es un elemento clave en el legado de Polanyi.

Toda su obra se enmarca en la voluntad de demostrar que es posible encontrar otros fundamentos en la actividad económica que vayan más allá de la dinámica tremendamente injusta de la sociedad industrial, que su misma experiencia personal le recordaba continuamente. En este sentido, las influencias de la obra de Marx (a la que recurría constantemente, pero de la que también le separaban algunos aspectos), o de la obra de Robert Owen y de otros socialistas fabianos, fueron esenciales. Es evidente que el énfasis con el que insiste en que la transformación social no podrá surgir desde "arriba", sino que deberá construirse desde las experiencias sociales, tiene un fondo a la vez de socialismo utópico y a la vez socialcristiano que caracterizó la trayectoria de Polanyi. En una cita que se le atribuye afirma: "El hombre no es un ser social porque vive en la sociedad, sino que el hombre vive en sociedad porque es esencialmente social. La 'sociedad' no es algo entre los hombres, ni encima de ellos, sino dentro de ellos,... por lo que la sociedad como realidad, no como concepto, es inherente en la conciencia de cada individuo". No es anecdótico tampoco en este sentido que Polanyi fuera un gran lector de Rousseau, al que dedicó un ensayo.

Se trasladó a Canadá primero, y después a Vermont, que es donde precisamente, gracias a una beca, pudo escribir "La Gran Transformación". Más tarde fue nombrado profesor de historia económica en la Universidad de Columbia, pero acabó instalándose definitivamente en Toronto (tras la negativa de las autoridades estadounidenses a conceder una visa permanente a su esposa Ilona, por su pasado comunista) desde donde se trasladaba a Nueva York. Se jubiló como profesor en Columbia en 1957, pero siguió investigando y escribiendo, gracias a una ayuda de la Fundación Ford, hasta su muerte en 1964 en Ontario, no sin haber recibido antes un homenaje en su Hungría natal.

La nueva "juventud" de Karl Polanyi

¿Como es posible que un libro escrito hace setenta años nos ayude a explicar muchas de las cosas que nos suceden?. Parece una pregunta retórica o nada original, ya que no empezamos nunca "solos" a tratar de dar respuestas a problemas que se nos presentan, a cada paso, como si fueran originales y totalmente nuevos. Afortunadamente, nos acompañan siempre aquellos que antes pensaron y debatieron sobre problemas que, con formatos y expresiones más o menos distintas, tienen raíces y dilemas parecidos. Podríamos decir que 
hay libros y aportaciones que se resisten a desaparecer. Lo que provocó que Karl Polanyi escribiera su obra más conocida, "La gran transformación" (LGT) en 1944 (primera edición en español en Fondo de Cultura Económica, 1992), fue lo que el mismo califica, en las primeras frases del libro, como el derrumbe de la civilización del siglo XIX. Una civilización que, en sus propias palabras, descansaba en cuatro instituciones: el equilibrio entre naciones (herencia westfaliana); el patrón oro y lo que implicaba de organización de la economía internacional; la idea del mercado autorregulado y su aparente capacidad para promover un gran desarrollo económico; y el Estado Liberal, como base de organización del sistema político.

Como puede verse, lo que a Polanyi le preocupaba, no está muy alejado de lo que ahora nos angustia y agita. Y más bien, lo que observamos es una profundización de los factores de crisis en cada uno de esos entramados institucionales. El escenario internacional funciona cada vez menos en la lógica de lo que quiso ser la "pax" westfaliana. La economía internacional presenta formatos de funcionamiento que difícilmente permiten encuadramientos institucionales fundamentados en una menguante capacidad de los estados para afrontar esa misión. La hipótesis de un mercado autorregulado, resulta hoy casi obscena, observando lo que acontece, con constantes intervenciones estatales que buscan con ahínco una autorregulación que los mercados financieros globales son capaces de dinamitar al instante. Las aportaciones de Polanyi son pues muy significativas, más que como respuestas concretas a problemas contemporáneos, como fuente de inspiración y reflexión para nuestra propia búsqueda.

\section{Polanyi, la "crisis" y la autonomía de lo económico}

No parece que podamos simplemente denominar como "crisis" el conjunto de cambios y transformaciones por el que están atravesando, en mayor o menor medida, las sociedades contemporáneas. Parece más correcto describir la situación como la de transición o de "interregno" entre dos épocas. Las alteraciones son muy significativas en el escenario económico y laboral, pero también en las esferas más vitales y cotidianas. Existen discontinuidades sustantivas. La creciente globalización mercantil, informativa y social, traslada problemas e impactos a una escala desconocida. Somos más interdependientes en los problemas, y tenemos menos vías abiertas y fiables para la búsqueda de soluciones colectivas en cada país ${ }^{2}$.

El gran sustrato que lo altera todo y que, al mismo tiempo, parece hacerlo todo posible es Internet y la sacudida tecnológica que conlleva. Hasta ahora, en muchos casos, se ha operado como si esa transformación tecnológica permitiera simplemente hacer mejor lo que ya hacíamos pero con nuevos instrumentos. Pero, todo indica que la transformación es mucho más profunda. Lo que viene aconteciendo en los últimos tiempos (decisiones de gran calado económico y social tomadas fuera de los marcos normativos establecidos; incapacidad de los poderes públicos para afrontar alteraciones profundas de su cuadro macroeconómico; graves recortes en las políticas sociales que convierten en papel mojado derechos considerados intocables,...), confirma que los efectos del cambio tecnológico y su aprovechamiento por parte de quiénes quieren maximizar sus beneficios, van a ir mucho más allá de sus ya importantes impactos en la producción, en la movilidad y el transporte, o en la potenciación de la deslocalización.

Tenemos precedentes bien significativos de lo que implicaron cambios tecnológicos, productivos y sociales como los que ahora vemos iniciarse y afianzarse. Como bien explica Polanyi, la aparición del "molino satánico", contribuyó decisivamente al impulso de la mercantilización del trabajo y de la tierra, obligando además a cambios en la organización productiva generados por la intensificación comercial. En una primera fase, el desarrollo de la industria lanar a nivel doméstico, fue ya una revolución en el marco de condiciones de vida de aquellos que dejaban la pobreza, pero también la certeza y la seguridad de los enclaves locales, para aventurarse en el nuevo mundo del trabajo industrial. El aumento de la demanda de lana impulsó los cercamientos de las tierras comunales, entendiendo que ello era una palanca imprescindible para potenciar la

${ }^{2}$ Es significativo en este sentido ver como Polanyi en su obra LGT trabajaba asimismo con parámetros esencialmente globales, evitando el etnocentrismo, lo que le da a su obra y a muchos de sus comentarios o acotaciones una gran actualidad. 
producción y de esta manera el crecimiento económico, y el aumento del comercio generaba también nuevas oportunidades de empleo para quienes perdían sus antiguas ocupaciones, eliminándose así la base de tierras comunales que garantizaba la subsistencia.

Para Polanyi, el impacto de la implantación de las máquinas, el impacto del cambio tecnológico, resultó clave en el establecimiento del mercado autorregulado, al desincrustar la economía del habitat social concreto de cada persona, en el que existían no sólo formas de intercambio, sino también de redistribución y de reciprocidad. El coste de maquinaria sofisticada y de plantas de producción, propias de la segunda revolución industrial o fordista, exigían producir una gran cantidad de bienes, y, consecuentemente, un flujo continuo de materias primas. Todos los factores involucrados en la producción "deben estar disponibles para cualquiera que esté dispuesto a pagar por ellos". El volumen de riesgo acaba siendo tan significativo que será "la comunidad en su conjunto que pasará a depender de la producción continua de ingresos, empleos y provisiones" (POLANYI, 2003, p. 89). Se pasa así de la motivación en la acción de cada quién en razón a la subsistencia, a la motivación por la ganancia, lo que la convierte en ilimitada. En algo "no natural para el hombre" (Aristóteles), al divorciar (desincrustar) la motivación económica de las relaciones sociales en la que se daba la producción. La conclusión a la que llega Polany es clara: "la sociedad humana se había convertido en un accesorio del sistema económico" (p. 125).

Como afirma Laville (2012) glosando a Polanyi, la economía de mercado, cuando no tiene límites, conduce a la sociedad de mercado, y acaba siendo la base de su organización y funcionamiento. La búsqueda del interés privado garantizaría así el bien público, obviando pues la necesidad de deliberación política. Lo que Polanyi denuncia es que esa utopía de mercado autorregulado, desincrustado socialmente, que caracteriza la modernidad democrática, y que la distingue de otras sociedades humanas que si bien disponían de mecanismos de intercambio mercantil, no los habían convertido en sistemas autónomos y omnicomprensivos. Cuando la visión económica del mundo pasa a convertirse en un fin en si mismo, lo que ocurre es que se niega a los procesos democráticos la posibilidad de decidir y definir un sentido y un proyecto humano. Frente al McWorld sólo quedaría la Yihad (BARBER, 1996), sin espacio para la política.

\section{¿Alternativas?}

Estamos instalados en pleno proceso de transición o de interregno entre la segunda y la tercera revolución industrial (THE ECONOMIST, 21-04-2012). La revolución digital e Internet están poniendo las bases de otro modelo de producción, distribución y consumo. Las nuevas capacidades tecnológicas permitirán una menor dependencia de las estructuras de intermediación fabril a las que llegaban materias primas y de la que salían productos manufacturados, usando la forzada concentración de mano de obra. El fordismo, construido sobre la estructura de la industria doméstica y parroquial que nos describe Polanyi, puso en pie un gigantesco y costoso (en términos de inversión y de costes sociales) mecanismo de intermediación productiva, capaz de proveer de bienes de consumo a grandes masas de población a las que anteriormente les estaba vedado su acceso. Esa "democratización" del consumo, tenía como objetivo el vincular "habitat" (seguridad socioeconómica de las personas en su entorno natural) y "mejora" (posibilidad de aumentar calidad de vida y beneficio) (en términos de Polanyi), pero acabó comportando una clara degradación del "habitat" y el incremento de la desigualdad, generando a la postre un movimiento para una mejor "incrustación" de economía y sociedad, a partir de la gran capacidad de intervención por parte de una fuerza de trabajo concentrada y organizada. Con la consiguiente dificultad para seguir manteniendo la tasa de ganancia del capital. En estos momentos, mientras por una parte el capitalismo ha buscado en Internet el como seguir manteniendo altas tasas de ganancia, desplazando buena parte de su centro de gravedad de la producción a la especulación financiera y monetaria, empiezan también a ser posibles otras alternativas aprovechando esa misma revolución tecnológica.

Aquí también Polanyi resulta sugerente. Cada movimiento desregulador es respondido por iniciativas sociales que buscan "incrustar", inscribir el funcionamiento de la economía en reglas que aseguren el respeto al marco democrático. Volvemos a estar en momentos en que la sociedad de mercado amenaza a la 
democracia. Ello ocurre cuando la lógica del beneficio material se vuelve única e ilimitada. Las respuestas, sugiere Polanyi, deben buscarse no en modelos construidos desde arriba, sino en prácticas sociales que apunten a la reinscripción de la economía en normas democráticas. La fuerza de la respuesta mercantil a todo tipo de interacción social, responde a lo que la modernidad supuso de ruptura con mecanismos tradicionales de regulación social que mezclaban reciprocidad, redistribución e intercambio. El mercado resuelve de manera simple procesos de coordinación que resultarían más complejos a la escala en que se plantean. Pero, la economía mercantil no ha podido hacer realidad la promesa de armonía social, de bienestar colectivo, que decía incorporar. Más bien al contrario. La pervivencia y recrudecimiento de la cuestión social pone en evidencia la necesidad de promover formas e instituciones capaces de contrarrestar sus efectos nocivos.

Podemos imaginar otros escenarios, y lo podemos hacer a partir de la relectura de Polanyi y de las oportunidades del cambio de época. La lectura del reciente prólogo que hizo Elinor Ostrom, la politóloga y premio Nobel de economía del 2009, de la última edición en español de su obra "El gobierno de los bienes comunes", permite establecer puentes significativos entre la más relevante teórica del tema de bienes comunes desde una perspectiva medioambiental y natural, y las aportaciones de Polanyi. Ostrom afirma que la teoría convencional sobre los recursos de propiedad colectiva supone que cuando las personas se enfrentan a un dilema generado por otros, reaccionarán aplicando la lógica de "homo economicus", estableciendo cálculos estrechos y de corto plazo que conllevarán a los individuos a dañarse a si mismos y a los otros sin poder encontrar maneras de cooperar entre todos para resolver el problema (OSTROM, 2011, p. 12). En este sentido, la obra de Polanyi nos muestra como se construyó teóricamente la falacia de la correspondencia natural entre la perspectiva egoísta y la lógica competitiva. Para Polanyi, la economía es "un proceso instituido de interacción entre el hombre y su entorno, cuyo resultado es un continuo abastecimiento de medios materiales para satisfacer las necesidades" (POLANYI, 2012). Y para ello postula, al final de LGT, la necesidad de sacar el trabajo humano, la tierra y la información y el conocimiento de la lógica de mercado, y recolocar a los poderes públicos en su capacidad de organizar la emisión monetaria, el crédito o la inversión. En esas líneas estratégicas, Polanyi coincide con la las líneas centrales de la economía social y solidaria, en su búsqueda de un sistema distinto al del mercado y la competencia como fundamentos económicos, poniendo en valor la reciprocidad y la redistribución, junto con el interés, como tres polos económicos que pueden entrelazarse de distintas maneras. Es esa mirada de economía plural que necesitamos para evitar seguir arrostrando los graves costes de la desincrustación social de la economía mercantil.

Decía Castoriadis que "el capitalismo vive agotando las reservas antropológicas constituidas durante los milenios precedentes" (2006). En estas páginas hemos tratado de contribuir al debate de cómo construir alternativas que no pasen por caminos ya agotados. El procomún, la economía social, pueden constituir alternativas que pongan en valor lo ya existente en muchos campos y que permita explorar nuevas articulaciones en una lógica de economía plural. Parce claro que la política, en su capacidad de gestionar de manera pacífica y consensuada la toma de decisiones que afectan a una comunidad, padece de manera directa el gran impacto que genera el proceso de cambio de época en el que estamos inmersos. Necesitamos un cambio profundo en la concepción de la democracia. Vinculándola, incrustándola, a las dinámicas económicas, ambientales y sociales. Incorporando las potencialidades del nuevo escenario que genera Internet, e incorporando a la ciudadanía de manera directa, comunitaria y autónoma a la tarea de organizar las nuevas coordenadas vitales $\mathrm{Y}$ ello nos obliga, evidentemente a hablar, discutir y experimentar nuevas formas de producción, de subsistencia, de vida.

El problema esencial sigue siendo el cómo producir y distribuir lo necesario para vivir. Las aportaciones de Polanyi resurgen como pautas a explorar. No parece que ni el mercado, en su configuración global y financiera, ni el estado, en su vertiente más jerárquica y autista, sean capaces de afrontar esa tarea con posibilidades de éxito. Lo común, aparece como una alternativa viable desde las diferentes perspectivas (social, económica, cultural y ecológica), para asumir los nuevos retos, desde la corresponsabilidad social y la articulación medioambiental. Las dudas surgen sobre la posibilidad que principios como solidaridad, calidad de vida o sostenibilidad ecológica sean capaces de constituir las bases de la renovación política y democrática que nuestro mundo requiere. No parece que la evolución del mercado, con sus lógicas especulativas y estrictamente financieras, y el desconcierto de muchos estados ante una realidad económica y 
social que se escapa a sus estructuras soberanas, permitan afrontar sin traumas los retos planteados. En esa línea queda mucho por discutir y debatir, pero las aportaciones de Polanyi ofrecen una perspectiva absolutamente significativa en esa labor.

\section{Referencias:}

BARBER, B. Jihad vs. "McWorld”. New York: Ballantine Books, 1996.

CASTORIADIS, C. Una sociedad a la deriva. Entrevistas y Debates (1974-1997). Buenos Aires: Katz Editores, 2006.

CORAGGIO, J. L. Karl Polanyi y la otra economía en América Latina, En: POLANYI, K. Textos escogidos. Buenos Aires: CLACSO-UNGS, 2012. 47-82 p.

LAVILLE, J. L. Actualidad de Karl Polanyi. En: Textos escogidos. Buenos Aires: CLACSO-UNGS, 2012. 13$20 \mathrm{p}$.

MENDELL-K. M.; POLANYI, L. Karl Polanyi: su vida y época. En: Textos escogidos. Buenos Aires: CLACSO-UNGS, 2012. 21-46 p.

OSTROM, E. A General Framework for Analizing Sustainability of Socio-cological Systems. Science, v. 325, n. 5939, p. 419-422, Julio, 2009.

El gobierno de los bienes comunes. La evolución de las instituciones de acción colectiva. Ciudad de México: Fondo de Cultura Económica, 2011.

POLANY, K. La gran transformación. Los orígenes políticos y económicos de nuestro tiempo. México: FCE, 2003.

El sustento del hombre. Madrid: Capitán Swing, 2009.

Textos escogidos. Buenos Aires: CLACSO-UNGS, 2012. 